\title{
Wheatgrass Extractor Performance and Its Effect on Fermented Beverage Product Results
}

\author{
Maynanda Brigita Chrysta1), Eun-Suk Lee ${ }^{1)}$, Tae-Hoon Kim²), Won-Sik Choi3)
}

\begin{abstract}
Wheatgrass is one type of young grass that contains many nutrients that are beneficial to the body due to its vitamin, mineral, protein, and phytochemical properties. However, this plant still not has many scientific data related to the development of its products. As an alternative to the development product of this plant, the fermentation process can be conducted. Before the fermentation, the extraction process was done first in this study. Extraction was carried out to obtain wheatgrass extract which will be used as an ingredient in making fermented drinks. The extraction variations conducted in this study were distinguished based on the extractor system. There were two types of extractors used, the twin-gear type and the squeezing type. The performance of extractor was analyzed by the yield, processing capacity, and extraction rate. The quality of wheatgrass extracts obtained was also analyzed before used as an ingredient to make wheatgrass fermented beverages. In the fermentation, the initial sugar content of the sample was controlled at $24 \%$. The quality of extraction and fermentation product was analyzed by its physicochemical properties, such as TSS, pH, and acidity content. From the results obtained, both of the extractor performance and the quality of product, it can be concluded that to obtain the best quality of wheatgrass fermented beverage was by using twin-gear type extractor as the appropriate extractor with the yield, processing capacity, extraction rate, TSS content, $\mathrm{pH}$, and acidity content were $73.03 \pm 2.25 \%, \quad 0.44 \pm 0.05 \mathrm{~g} / \mathrm{s}, \quad 0.16 \pm 0.01 \mathrm{~g} / \mathrm{s}, \quad 21.80 \pm 0.20 \%$, $4.223 \pm 0.006$, and $1.14 \pm 0.06 \%$, respectively.
\end{abstract}

Keywords: Wheatgrass, Extractor, Performance, Fermented Beverage, Quality, Product

\section{Introduction}

Wheatgrass (Triticum aestivum) is one type of young grass that lately have known rich in nutrients because it is many times richer in vitamins, minerals, and protein compared to seed kernel or grain products from mature cereal plants[1]. Ben et al.[2], and Ferruzia and Blakesleeb[3] reported that regular consumption of wheatgrass extract can improve the digestive

Received(September 18, 2019), Review Result(1st: October 13, 2019, 2nd: November 25, 2019), Accepted(January 30, 2020)

1) (Student) 50463 Dept. Bio Industrial Machinery Engineering, Pusan National University, Miryang, Korea email: maynandabc@pusan.ac.kr

2) (President) 440310 Greenpower Juicer Co. Ltd., Suwon, Korea

email: green@greenpower.co.kr

3) (Professor, Corresponding Author) 50463 Dept. Bio Industrial Machinery Engineering, Pusan National University, Miryang, Korea

email: choi@pusan.ac.kr 
system and the general welfare. Another study was also reported that wheatgrass juice can inhibit hematological toxicity related to chemotherapy in breast cancer patients[4].

Even so, this plant is still said to not have many scientific data related to product development. The most widely consumed product development so far is only in the form of fresh products or frozen juice[5]. Therefore, Therefore, it is important to study the properties or even food processes that can be applied to further explore the benefits of this plant.

One of the basic processes known as the separation techniques commonly used by the food industry, especially for foods that are very sensitive to heat is extraction. Extraction has been applied to wheatgrass as the beginning process of making wheatgrass powder[6]. The extraction results can also be used and developed as ingredients to make other products, including to make fermented beverage or vinegar, considering the consumption of this product that also high around the world.

Fermentation is a slow decomposition process of organic substances and the conversion of carbohydrates into alcohols or organic acids by microorganisms or enzymes[6]. The purpose of this process is usually to extend the life of food consumption, modify the physical and chemical properties of the ingredients, improve the taste quality, and also increase the nutritional content of the ingredients. The type of fermentation commonly used for vegetables and fruits is lactic acid fermentation. Lactic acid (LA) fermentation is also known to be carried out to maintain and enhance the nutritional and sensory features of food commodities[7].

Extract products as fermentation ingredients are predicted can make the fermentation easier. Even so, the quality of the extracted product will also still affect fermentation. One factor that is known to influence extract quality is the extraction method used. Pareek et al.[8] in their study also proved that variations in extraction methods carried out could affect the quality of the resulting mandarin juice. Therefore, in this study, an observation was carried out on the fermentation using wheatgrass extract obtained to produce quality fermented beverages.

\section{Materials and Methods}

\subsection{Extraction of Wheatgrass}

The wheatgrass used in this study was provided by Greenpower Juicer Co. Ltd. The wheatgrass used for extraction was cleaned by tap water and hand-sorting from other materials, then extracted. There were two types of extractor used in this experiment, the twin-gear type (Green Power Extractor Juice KP-E1304, Green Power, Korea) and the squeeze 
type (Hurom Juice Extractor Slow Juicer type Classic series, Hurom, Korea). The extractor used can be seen in Figure 1. The difference between these two extractors is the technology used in the machine, which is the Green Power extractor uses a twin-gear technology, while the Hurom Juice extractor uses the auger technology (slow squeeze technology) (Fig.2).

The amount of wheatgrass used for extraction were two-hundred grams $(200 \mathrm{~g})$. In the extraction process, water or other additives were not used to obtain pure extracts. Regarding analyzing the performance of the extraction machines used, the extraction process time for each machine was also recorded. The extract obtained was also weighed before analyzing its physicochemical properties. After the analysis was complete, the extract was then used as a fermentation ingredient. The extraction process was carried out in triplicate for each variation.

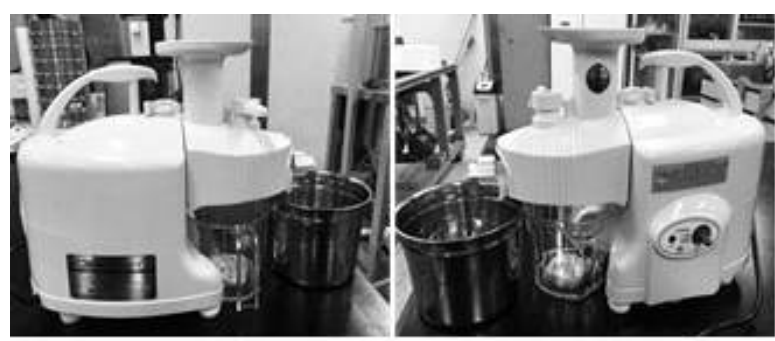

(a)

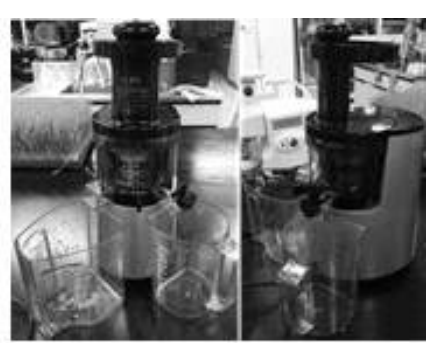

(b)

[Fig. 1] Extractor used: Green Power Extractor Juice KP-E1304 type (a) and Hurom Juice Extractor Slow Juicer type Classic series (b)

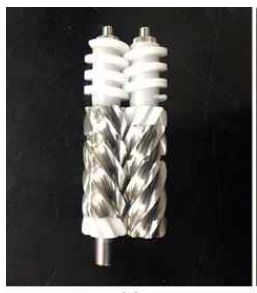

(a)

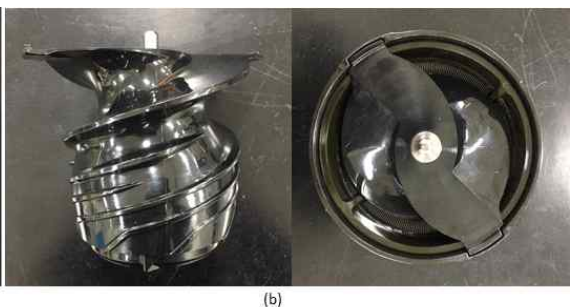

(b)

[Fig. 2] Twin-gear used on the Greenpower extractor (a) and auger tools on the Hurom extractor (b)

\subsection{Fermentation of Wheatgrass}

The extracts from $100 \mathrm{~g}$ of wheatgrass were put into a fermentation jar and added by distilled water in a ratio of 1:2. Wheatgrass extract as a fermentation material was filtered first to prevent any other unwanted ingredients. Sugar was added to the jar to get a solution with an initial sugar content of $24 \%$. Salt was added to the fermentation sample in a ratio of $1 \mathrm{~g} / \mathrm{L}$ 
and also the starter culture (Uinkin, Korea) was added at $2 \%(\mathrm{v} / \mathrm{v})$ to accelerate the fermentation process. The fermentation samples that have been mixed were then stored in a fermentation chamber with a temperature of $35^{\circ} \mathrm{C}$ for 8 days.

\subsection{Analysis}

The analysis conducted in this study consists of the extraction performance and the quality of the fermentation product. The extraction performance analysis consists of extract yield, processing capacity ( $\cap$ processing), and extraction rate. Extract yield is usually used as an indicator of the effects of the extraction conditions. The calculation of extract yield was following Dhanani et al.[9] method with equation (2.1). While the calculation for processing capacity and the extraction rate was following Hati[10] method by using the equation (2.2) and (2.3) below, respectively.

$$
\text { Extract yield }(\%)=\frac{W 1}{W 2} \times 100
$$

$$
\begin{aligned}
& \text { Where : } W 1=\text { weight of extract obtained }(\mathrm{g}) \\
& W 2=\text { weight of wheatgrass before extraction }(g) \\
& \cap \text { processing }(\mathrm{g} / \mathrm{min})=\frac{\text { mass of extract }}{\text { extractiontime }} \\
& \text { Extraction rate }(\mathrm{g} / \mathrm{min})=\frac{\in \text { ialmass of wheatgrass }- \text { mass of extract }}{\text { extractiontime }}
\end{aligned}
$$

The physicochemical properties of products obtained consists of total soluble solids (TSS) content, $\mathrm{pH}$ value, and acidity content. All of these analyses were done in triplicate to determine the accurate results for each sample. The TSS was measured by methods outlined in AOAC[11] by a refractometer (ATAGO, Japan). The $\mathrm{pH}$ was determined by using a $\mathrm{pH}$ meter (iSTEK, Korea). Meanwhile, the procedure for determining the total acidity followed the method of determining total acidity in vinegar by titration method written in Nielsen[12]. The titratable acidity was then calculated by the equation (2.4) and expressed as percent lactic acid.

Titratable acidity $(\%)=\frac{V \cdot N a O H(L) \times M \cdot N a O H \times M W}{\text { sample weight }(g)} \times 100$

Where : $M W=$ Molecularweight $=60.05 \mathrm{~g} / \mathrm{mol}$ 


\section{Results and Discussion}

\subsection{Extractor Performance}

Each extractor has its own characteristics which will also affect the extract results obtained. The twin-gear extractor was known to have a unique twin-gear triturating feature that uses an impeller press system. In this case, triturating is the process of destroying, grinding or pounding fresh fruits or vegetables well so that it can extract juice, nutrients, enzymes, and so forth[13]. While the slow-squeeze extractor use auger technology to minimize nutrient loss due to oxygen and friction exposure[14]. Therefore, the performance of the extractor used was observed. The results of extraction performance analysis for each type of extractor used can be compared in Table 1 below.

[Table 1] Wheatgrass Extractor Performance for Twin-gear and Slow Squeeze Type

\begin{tabular}{ccc}
\hline \multirow{2}{*}{ Characteristics } & \multicolumn{2}{c}{ Type of Extractor } \\
\cline { 2 - 3 } & $\begin{array}{c}\text { Twin-gear extractor } \\
\text { (Greenpower Juicer) }\end{array}$ & $\begin{array}{c}\text { Slow-squeeze extractor } \\
\text { (Hurom Juicer) }\end{array}$ \\
\hline Density $(\mathrm{g} / \mathrm{mL})$ & $0.93 \pm 0.01$ & $0.98 \pm 0.02$ \\
Extract Yield $(\%)$ & $73.03 \pm 2.25$ & $58.00 \pm 3.51$ \\
Processing capacity $(\mathrm{g} / \mathrm{min})$ & $26.42 \pm 3.02$ & $6.55 \pm 1.46$ \\
Extraction rate $(\mathrm{g} / \mathrm{min})$ & $9.71 \pm 0.60$ & $4.73 \pm 1.34$ \\
\hline
\end{tabular}

From Table 1 can be seen that although the density of wheatgrass extract from twin-gear extractor obtained was lower than the extracted result from the slow-squeeze extractor, the other characteristics of extraction process performance obtained using a twin-gear type extractor still gave higher results than other. Furthermore, the actual density value of wheatgrass extract obtained from the two variations of the extractor type was also not very different.

The observation results of the physicochemical properties for each type of extract obtained can be seen in Table 2 below. Observed from the sugar content (TSS), the extract obtained with the twin-gear extractor gave lower results compared to the extract obtained from the slow-squeeze extractor. This result was in accordance with the $\mathrm{pH}$ and acidity value of each extract, where twin-gear extract results had a higher $\mathrm{pH}$ value and lower acidity value than slow-squeeze extract results. This result also proved that there was a possibility that twin-gear extract results actually contained more nutrients other than slow-squeeze extract results because 
it is known there are some nutrients that are actually alkaline and do not contain much sugar.

[Table 2] Physicochemical Properties of Wheatgrass Extract Obtained

\begin{tabular}{ccc}
\hline & \multicolumn{2}{c}{ Type of Extractor } \\
\cline { 2 - 4 } Parameters & $\begin{array}{c}\text { Twin-gear extractor } \\
\text { (Greenpower Juicer) }\end{array}$ & $\begin{array}{c}\text { Slow-squeeze extractor } \\
\text { (Hurom Juicer) }\end{array}$ \\
\hline TSS (\%) & $4.47 \pm 0.75$ & $4.97 \pm 0.64$ \\
pH & $7.68 \pm 0.37$ & $7.66 \pm 0.44$ \\
Acidity $(\%)$ & $0.60 \pm 0.04$ & $1.20 \pm 0.00$ \\
\hline
\end{tabular}

Based on the results obtained generally, the extraction process using the twin-gear extractor type gave the best results. This can be happened due to the twin-gear system used in the machine. Wheatgrass belongs to the type of grass that has a thin and long texture. The twin-gear system used on the Green Power extractor is known to be able to extract materials, which even up to small particles of the material can also undergo a more powerful crushing or grinding process. During the process using this system, it was also known that no friction occurs, especially between the twin-gear, in contrast to the process that occurs in a slow-squeeze system. If using a slow-squeeze system, the friction that occurred during the process was known to be quite a lot, including friction between the materials and auger tool used. Therefore the twin-gear extraction system can provide better extract results than the slow-squeeze system.

\subsection{Wheatgrass Fermentation}

Fermentation is a food processing by breaking down organic compounds contained in an ingredient to produce energy and also new products by microbes[15]. Fermentation is known as food processing which is often used in product development. In this study, fermentation was also done for predicting the effect of the extractor used to the quality of the extract obtained if it wants to be further processed. This process was expected to be one of the other alternatives for product development for wheatgrass. Considering that fermented beverages are quite popular in almost many countries.

In this study, an additional fermentation powder (Uinkin, South Korea) was used. The addition of fermented powder was done to accelerate the fermentation process and increase the efficiency of fermentation[16]. The sugar contained in the sample will later be used by yeast to 
produce alcohol and carbon dioxide. On the fermentation process, a parameter usually used for checking the condition is the TSS content of the product. TSS content is also showing the sugar content of the solution that can be measured by a refractometer.

Based on the TSS analysis results obtained (Fig.3), it can be seen that in general, the TSS content for fermentation samples of wheatgrass extract experienced a reduction from $24.23 \%$ to $21.80 \%$ for twin-gear extract and from $23.57 \%$ to $22.23 \%$ for slow-squeeze extract, where was known that the best reduction by using the twin-gear extractor type. This result was consistent with the previous theory about the reduction in sugar content occurs during the fermentation process. The decrease of TSS occurred because the microbes or yeast in the sample will convert the sugar into ethyl alcohol and carbon dioxide[17]. The enzymatic hydrolysis decreased the polysaccharide amount and increased reducing sugars and soluble solids, thereby improving the fermentation process[18].

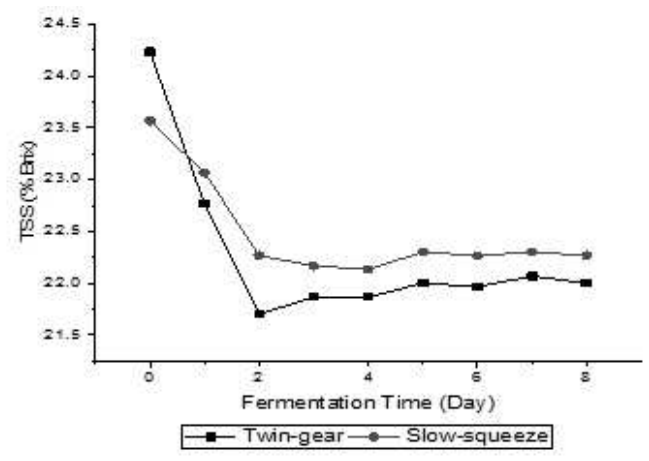

[Fig. 3] Changes of TSS Content during 8-days Fermentation

In the fermentation process, the alcohol and carbon dioxide content in the sample obtained as a result of sugar conversion will then be converted to acid by lactic acid bacteria. For the $\mathrm{pH}$ condition of the fermented product, Adegunloye and Famolu[19] reported that during fermentation $\mathrm{pH}$ decreases as sugars are consumed and reach a stable point when they are exhausted, at which time fermentation considered complete. The results of $\mathrm{pH}$ value analysis can be seen in Figure 4 below.

From Figure 4, it can be seen that there was a decrease in the $\mathrm{pH}$ value for all types of samples during the process. The $\mathrm{pH}$ value of the sample using the extract from the twin-gear extractor type and squeeze extractor type was decreased from 7.423 to 4.223 and 7.473 to 4.273 units on average, in sequence. Although the difference was not too high, Figure 4 can describe that the fermentation results from the twin-gear extract still gave a better decrease in the $\mathrm{pH}$ value than the fermentation from the slow-squeeze extract. 


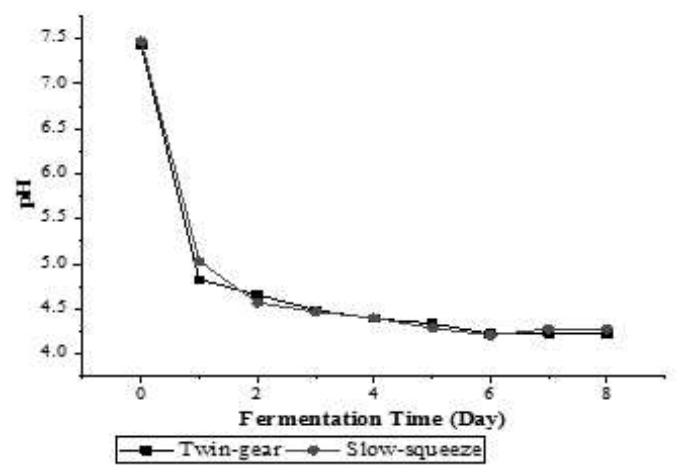

[Fig. 4] Changes of $\mathrm{pH}$ Value during 8-days Fermentation

Besides the $\mathrm{pH}$, there was another parameter related to this $\mathrm{pH}$ value, it is acidity. However, $\mathrm{pH}$ and titratable acidity can represent a different matter. In general, the $\mathrm{pH}$ relates more to things like microbial stability and susceptibility to mold and bacterial spoilage, whereas titratable acidity relates to the acid taste, amount of acid in the product[20]. Therefore, this acidity level becomes another parameter that illustrates the conversion process that occurs from alcohol and carbon dioxide contained in the fermentation sample that reacts with water vapor and forms carbonic acids. One of the main organic acids produced from the fermentation process is acetic acid. The higher the content of acetic acid contained, the higher the acidity.

The changes in acidity level for each sample during fermentation is shown in Figure 5. The acidity level of fermented wheatgrass extract from twin-gear extractor type and slow-squeeze extractor type increased from $0.24 \%$ to $1.14 \%$ and $0.21 \%$ to $1.05 \%$, respectively. In general, the acidity level given tends to increase with the time of the fermentation process. The results showed wheatgrass extract using the twin-gear extractor type provided the best increase in comparison to extract obtained from the slow-squeeze extractor type.

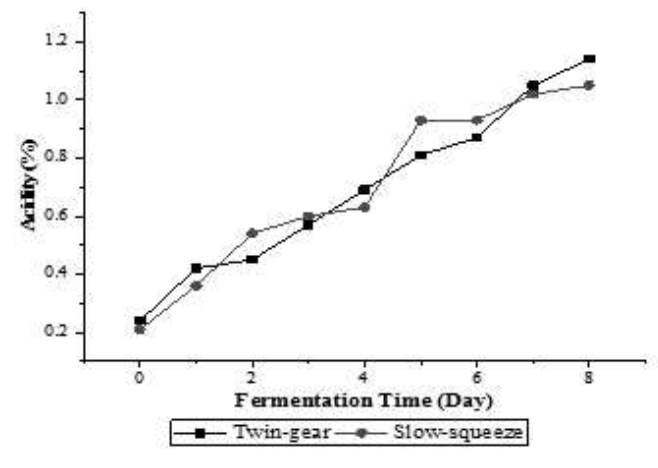

[Fig. 5] Changes of Acidity Level during 8-days Fermentation 


\section{Conclusion}

According to the analysis results of extractor performance and the quality of the product, both of extract and fermented beverage, it can be concluded that the appropriate extractor to obtain the best quality of wheatgrass extract and fermented beverage was by using twin-gear type extractor with the yield, processing capacity, extraction rate, TSS content, $\mathrm{pH}$, and acidity content were $73.03 \pm 2.25 \%, \quad 0.44 \pm 0.05 \mathrm{~g} / \mathrm{s}, \quad 0.16 \pm 0.01 \mathrm{~g} / \mathrm{s}, \quad 21.80 \pm 0.20 \%, \quad 4.223 \pm 0.006$, and $1.14 \pm 0.06 \%$, respectively. However, if only observed by the fermentation process, the variation of extractor used in this study did not have big significance differences for each parameter analysis results, especially on the $\mathrm{pH}$ and acidity level.

\section{References}

[1] P. R. Tirgar, B. L. Thumber and T. R. Desai, Isolation, Characterization and Biological Evaluation of Iron Chelator From Triticum aestivum (Wheat Grass), International Journal of Pharma and Bio Sciences, (2011), Vol.2, No.4, pp.288-296.

[2] E. Ben-Arye, E. Goldin, D. Wengrower, A. Stamper, R. Kohn and E. Berry, Wheatgrass Juice in The Treatment of Active Distal Ulcerative Colitis: A Random Double-blind Placebocontrolled Trial, Scand J. Gastroenterol, (2002), Vol.37, No.4, pp.444-449. 10.1080/003655202317316088

[3] M. G. Ferruzzia and J. Blakesleeb, Digestion, Absorption and Cancer Preventive Activity of Dietary Chlorophyll Derivatives, Nutrition Research, (2007), Vol.27, No.1, pp.1-12. https://doi.org/10.1016/j.nutres.2006.12.003

[4] G. BarSela, M. Tsalic, G. Fried and H. Goldberg, Wheat Grass Juice May Improve Hematological Toxicity Related to Chemotherapy in Breast Cancer Patients: A Pilot Study, Nutrition and Cancer, (2007), Vol.58, No.1, pp.43-48. https://doi.org/10.1080/01635580701308083

[5] R. Vijayalkshmi and P. Aishawarya, Phytochemical Characterization and Anti Cancer Activity of Triticum Aestivum L. (Wheat Grass), Life Science Research, (2018), Vol.2, No.10, pp.1-4.

[6] FAO, Fermented Fruits and Vegetables-A Global Perspective, FAO Agricultural Services Bulletin, (1998), Vol.134, Rome, Italy.

[7] N. S. Terefe, Food Fermentation, Reference Module in Food Science, Elsevier, (2016), https://doi.org/10.1016/B978-0-08-100596-5.03420-X

[8] S. Pareek, R. Paliwal and S. Mukherjee, Effect of Juice Extraction Method and Processing Temperature-time on Juice Quality of Nagpur Mandarin (Citrus reticulate Blanco) During Storage, Journal of Food Science and Technology, (2011), Vol.48, No.2, pp.197-203. https://doi.org/10.1007/s13197-010-0154-6 
[9] T. Dhanani, S. Shah, N. A. Gajbhiye and S. Kumar, Effect of Extraction Methods on Yield, Phytochemical Constituents and Antioxidant Activity of Withania somnifera, Arabian Journal of Chemistry, (2017), Vol.10, Supplement 1, pp.S1193-S199. https://doi.org/10.1016/j.arabjc.2013.02.015

[10] F. I. P. Hati, Effect of Feed Rate to Spray Dryer Performance and Quality of Serisin Powder from Silkworm Cocoon, UGM, Indonesia, Undergraduate Thesis, Department of Agriculture and Biosystem Engineering, (2017)

[11] W. Horwitz, G. W. Latimer, Official methods of analysis of AOAC International, 18th edition, AOAC International, (2005)

[12] S. S. Nielsen, Food Analysis, Springer, (2014)

[13] https://juicing-for-health.com/green-power-juicer, Sep 22 (2018)

[14] https://www.globalhurom.com/why-hurom/technologies, Oct 26 (2017)

[15] K. U. Sankar, Extraction Processes. In: Conventional and Advanced Food Processing Technologies, John Wiley \& Sons, (2014), https://doi.org/10.1002/9781118406281.ch7

[16] S. R. Hwang, S. Destiani, S. H. Kwon, S. W. Chung, S. G. Kwon, J. M. Park, J. S. Kim and W. S. Choi, A Study on the Vinegar Fermentation Processes of Fresh Korean Ginseng Extract Using Mix Microbial Yinkin, Journal of The Korean Society of Industry Convergence, (2017), Vol.20, No.4, pp.345-350. https://doi.org/10.21289/KSIC.2017.20.4.345

[17] A. Crowe, Brix in Fermentation: Wine Wizard, Winemaker Magazine, Issue Aug/Sep 2016, California, (2016)

[18] Rodaa, L. Lucini, F. Torchio, R. Dordoni, D. M. De Faveri and M. Lambri, Metabolite Profiling and Volatiles of Pineapple Wine and Vinegar Obtained from Pineapple Waste, Food Chemistry, (2007), Vol.229, No.1, pp.734-742.

[19] D. V. Adegunloye and O. F. Famolu, Influence of Fermentation on The Nutritional Content of Cocoa Pod (Theobroma cacao L), Journal of Global Biosciences, (2016), Vol.5, No.1, pp.3408-3413.

[20] C. Jolicoeur, The New Cider Maker's Handbook, Chelsea Green Publishing, (2013) 